\title{
A METHOD FOR THE STRUCTURAL ANALYSIS AND DESIGN OF ARCHED REINFORCED MASONRY AND/OR CONCRETE STRUCTURES
}

\author{
D. LóPez LóPez ${ }^{1 *}$, P. RoCA ${ }^{2}$, A. LieW ${ }^{3}$, T. VAN Mele ${ }^{4}$ AND P. BLOCK ${ }^{4}$ \\ ${ }^{1}$ Department of Architectural Technology, Universitat Politècnica de Catalunya \\ david.lopez.lopez@upc.edu
}
${ }^{2}$ Department of Civil and Environmental Engineering, Universitat Politècnica de Catalunya
${ }^{3}$ Department of Civil and Structural Engineering, The University of Sheffield
${ }^{4}$ Institute of Technology in Architecture, Block Research Group, ETH Zurich

Keywords: Tile vault, masonry, reinforced brick, formwork, concrete shells, limit analysis, ELARM.

\begin{abstract}
Extraordinary architectural examples of shell structures have been built using reinforced masonry and concrete. The current sparse use of this construction type can be attributed, among other reasons, to a lack of simple design methods, tools and criteria. Extended Limit Analysis of Reinforced Masonry (ELARM) is a new method for the structural analysis and design of reinforced concrete, reinforced masonry or reinforced composite (masonry and concrete) arched structures. It is implemented computationally to create a flexible design and analysis tool, able to provide immediate graphical and intuitive results. The method is based on limit analysis but takes into account the material's limited compressive strength and the vault's cross-sectional bending capacity provided by the reinforcement as an equivalent increase of the thickness. The plastic theorems are then applied considering the new virtual boundaries of the vault's intrados and extrados.

ELARM is validated through the comparison of its predictions with the results of load tests on two full-scale composite barrel vaults. The vaults feature a structural system composed of a two-layered tile vault as an integrated formwork for a reinforced concrete layer. They were tested under vertical loading up to failure. Both the vertical and horizontal displacements of the vaults were monitored during the tests. The characterisation of the materials composing the vaults was also carried out to introduce the measured material properties and strengths in the equilibrium equations for the computation of the new virtual thickness.

This paper presents the new structural analysis and design method, its experimental validation and some practical design examples to show the potential of the tool. It offers an intuitive process of design in which shape can be adapted and optimised, also having the material properties and thickness, loads and reinforcement quantity and placement as variable parameters. The presented examples include reinforcement optimisation and form-finding procedures and the analysis of a non-compression-dominated structure.
\end{abstract}




\section{INTRODUCTION}

The combination of masonry and/or concrete with reinforcement, on its many variants, has produced influential and striking shell structures in the history of architecture [1]. These constructions were particularly in demand from the 1920s to the early 1960s [2]. Nowadays, they are uncommon due to the lack of straightforward structural analysis and design methods and the construction costs, specifically the cost of the formwork [3].

Current formworks for concrete shells are either expensive, complex and wasteful or have formal restrictions. A possible approach to the construction of expressive shells may be provided by the use of tile vaults as stay-in-place formwork for concrete shells [4], which could significantly reduce construction costs and material waste. Furthermore, tile vaults provide a high formal flexibility as they only require formwork at the boundaries, from which the rest of the vault can be built gradually by completing stable sections [5] [6].

The combination of masonry and reinforced concrete creates a new type of composite structure that needs new calculation methods and models to deal with the specific features of the system [7]. This paper presents a method for the structural analysis and design of arched reinforced masonry and/or concrete structures. The method is called Extended Limit Analysis of Reinforced Masonry (ELARM) and is an extension of the work by Roca et al. [8]. It is based on the modern formulation of limit analysis for masonry arches by Jacques Heyman in 1966 [9], but takes into account the finite compressive strength of the masonry and concrete as well as the tensile capacity of the embedded reinforcement [4].

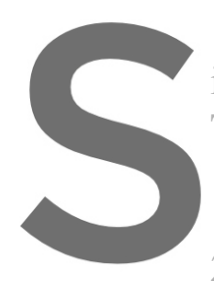

\section{ELARM is explainec in}

in Section 3, followed by

The conclusions are prest

\section{EXTENDED LIMITT ANA}
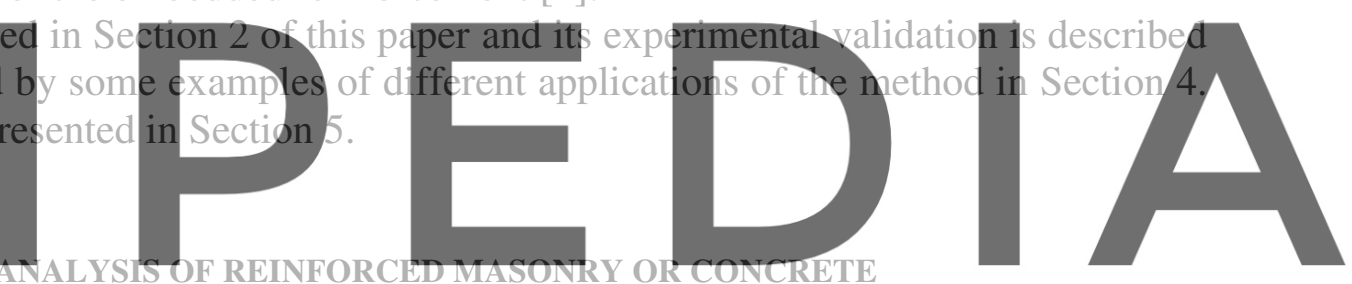

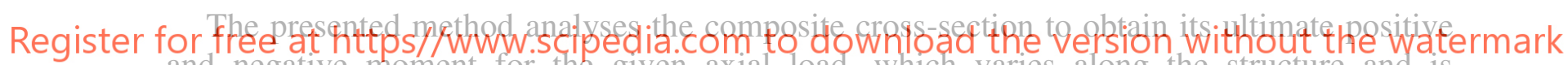
and negative moment for the given axial load, which varies along the structure and is determined by the self-weight and the external loads. The ratio between the ultimate moment and the axial load is equal to the maximum possible eccentricity (Figure 1). The eccentricity related to the positive moment defines the upper limit of the new virtual thickness and the eccentricity related to the negative moment defines the corresponding lower limit. As is done in the classical theory of limit analysis of masonry arches, the structure is divided in a number of virtual voussoirs, which allow the construction of the thrust line and sets the specific sections where axial forces, moments and eccentricities are calculated. ELARM is applicable for reinforced concrete, reinforced masonry and reinforced composite (masonry and concrete) arched structures, provided that the failure mode corresponds to that of a ductile mechanism characterised by the development of a sufficient number of hinges [4]. 


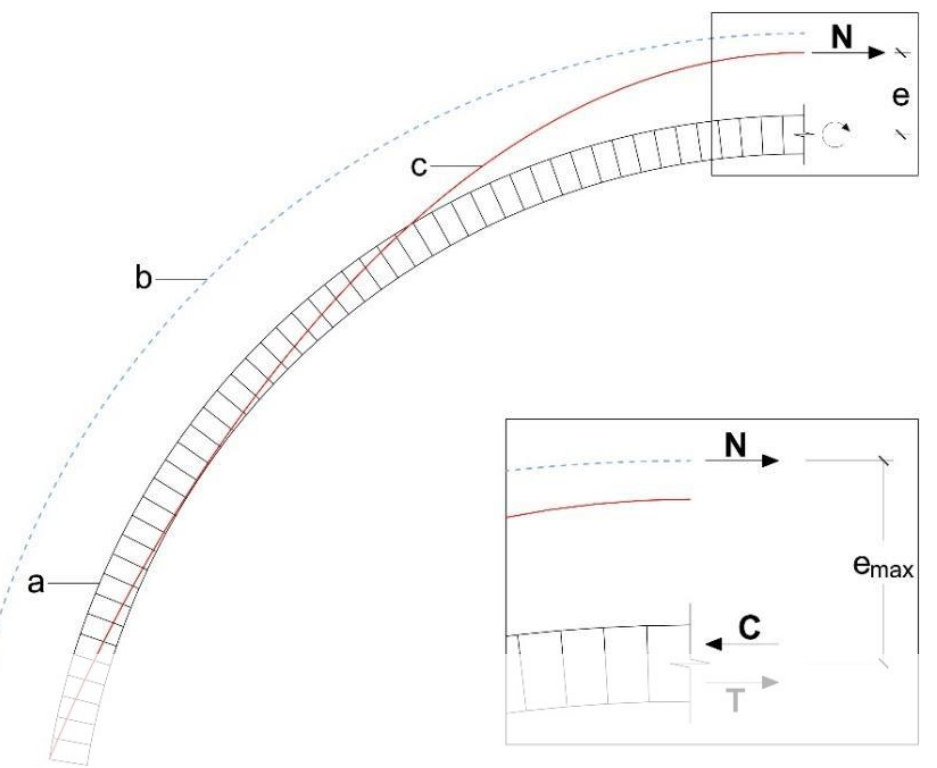

Figure 1: Thrust line located outside of the vault's thickness creating a bending moment; a) reinforced masonry and/or concrete arch, b) upper virtual thickness, and c) thrust line. Lower right) schematic distribution of forces for the ultimate positive bending moment.

The stability of the vault is verified when it is possible to find a thrust line, i with the applied loads, meaning that the safe the the collapse load and

The support conditions of the vault are of line and the stability of the vault. If the vault
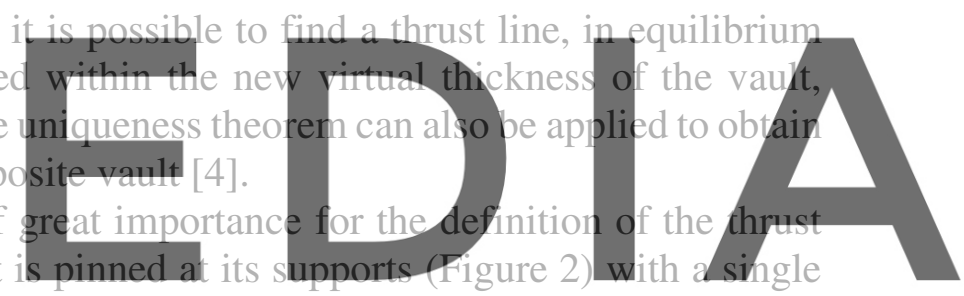

contact point, then the thrust line must pass through that point. In the case of a support consisting

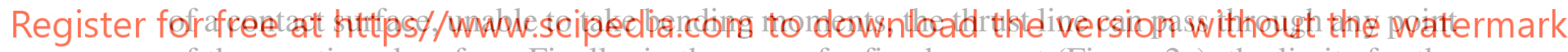
of the mentioned surface. Finally, in the case of a fixed support (Figure 2a), the limits for the thrust line at the supports coincide with the virtual thickness [4][8]. This method is applicable to reinforced concrete, reinforced masonry and reinforced composite (masonry and concrete) arched structures, provided that the failure mode corresponds to that of a ductile mechanism characterised by the development of a sufficient number of hinges.

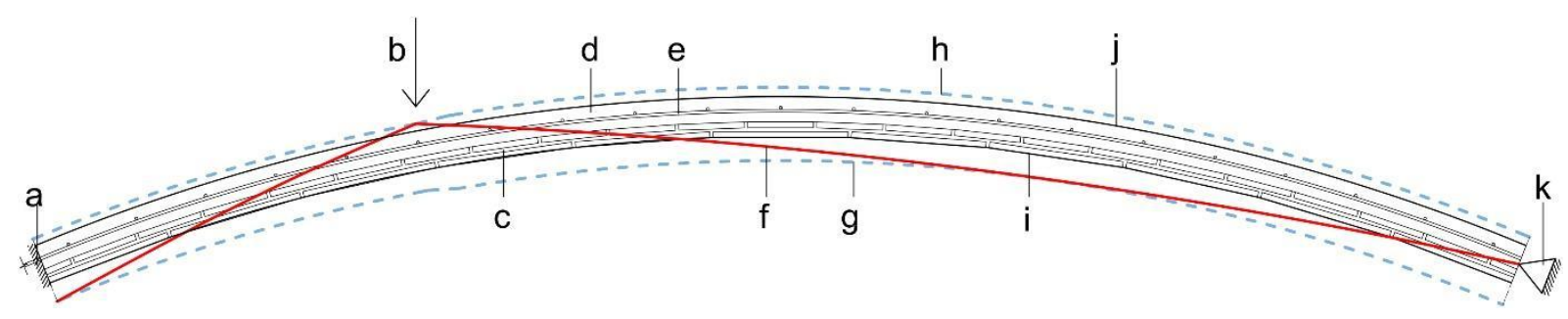

Figure 2: Application of uniqueness theorem with ELARM: a) fixed support, b) applied load, c) tile vault, d) concrete, e) reinforcement, f) thrust line, g) lower virtual thickness, h) upper virtual thickness, i) real lower thickness, j) real upper thickness, k) pinned support. 


\section{EXPERIMENTAL VALIDATION}

The presented method has been experimentally validated by comparing its results with those provided by the load-testing of full-scale prototypes. For these prototypes, the proposed technique of a tile vault as integrated formwork for steel-reinforced concrete was used. They were two composite cylindrical barrel vaults, with a span of $2.78 \mathrm{~m}$, a height of $0.25 \mathrm{~m}$, a width of $1 \mathrm{~m}$ and had pinned supports (Figure 3). A vertical load was applied at quarter span to a loading pad with a breath of $115 \mathrm{~mm}$ and stretching the entire width of the vault. The peak load for the first prototype was $52.43 \mathrm{kN}$, while it was $53.15 \mathrm{kN}$ for the second.

The material properties introduced in the model were obtained from compression and tensile tests on samples of the materials composing the vault. Tiles, fast-setting cement, mortar and concrete were tested in compression, whereas steel reinforcement was tested in tension. The compressive strength and unit weight of the tile vault resulted in $13.45 \mathrm{~N} / \mathrm{mm}^{2}$ and $2000 \mathrm{~kg} / \mathrm{m}^{3}$ respectively. Those of the concrete resulted in $22.20 \mathrm{~N} / \mathrm{mm}^{2}$ and $2460 \mathrm{~kg} / \mathrm{m}^{3}$. The mean yield tensile strength of the $6 \mathrm{~mm}$ diameter steel reinforcement was $581 \mathrm{~N} / \mathrm{mm}^{2}$ and the Young's Modulus was equal to $207000 \mathrm{~N} / \mathrm{mm}^{2}$. A detailed description of the material characterisation and the load tests can be found in López López et al. [4].
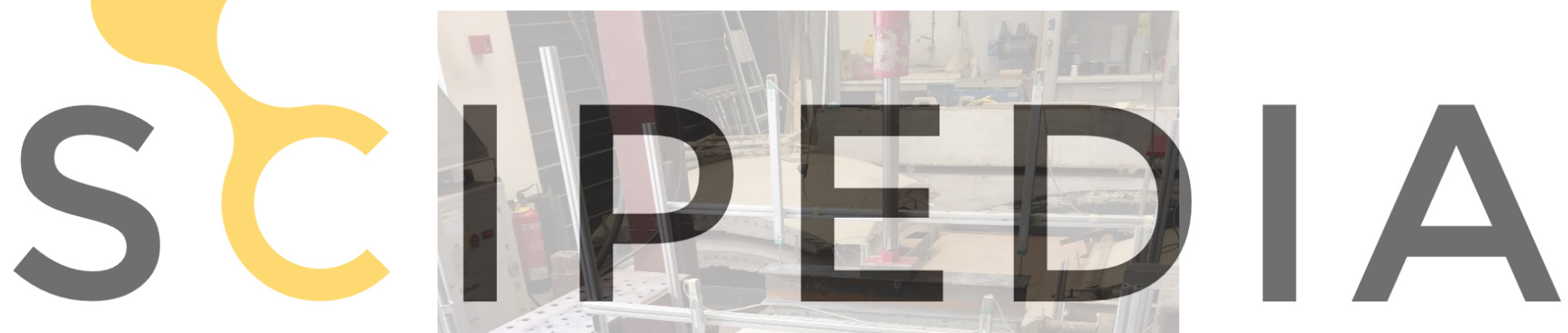

Register for free at https//WW/W.scipedia.com to download the version without the watermark

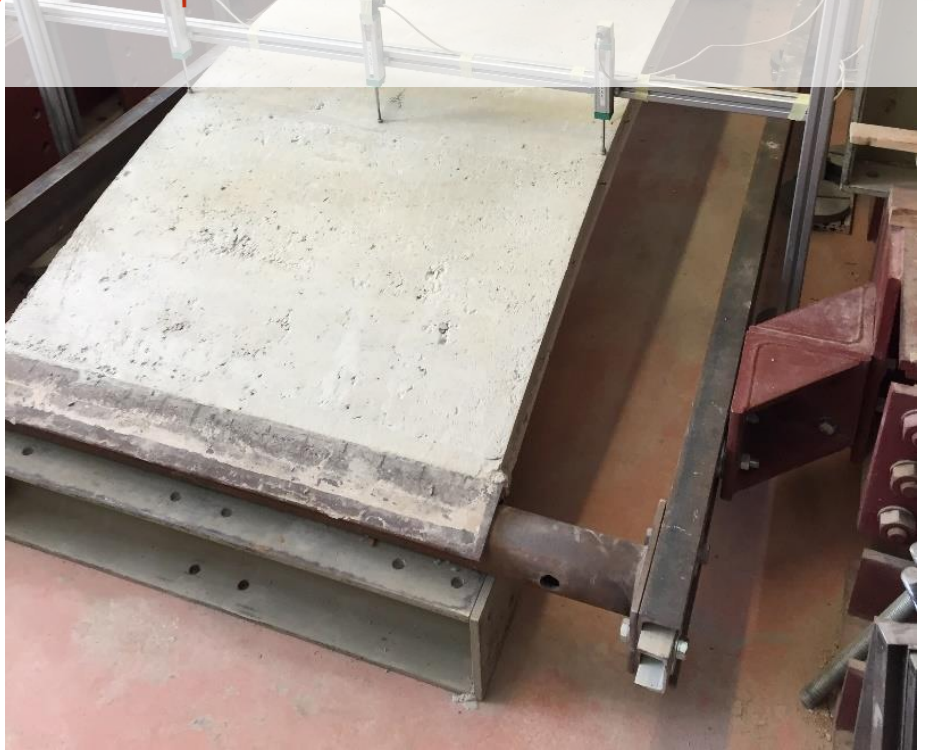

Figure 3: Photo of one of the full-scale prototypes. 
The geometry of the vaults and the material properties were introduced into the computational model to apply the uniqueness theorem and obtain the ultimate load carrying capacity of the vault (Figure 4). The thrust line's ends were set to the cross-section's centre line to represent the pinned support condition. The vault was divided into 100 voussoirs and the load was applied evenly as point loads onto four voussoirs at quarter span, replicating the 11.5 $\mathrm{cm}$ wide loading platform of the experimental tests. The load predicted by the numerical method is $53.6 \mathrm{kN}$ (Figure 4), which is $1.5 \%$ higher than the average of the two values obtained in the experimental tests, $52.8 \mathrm{kN}$.

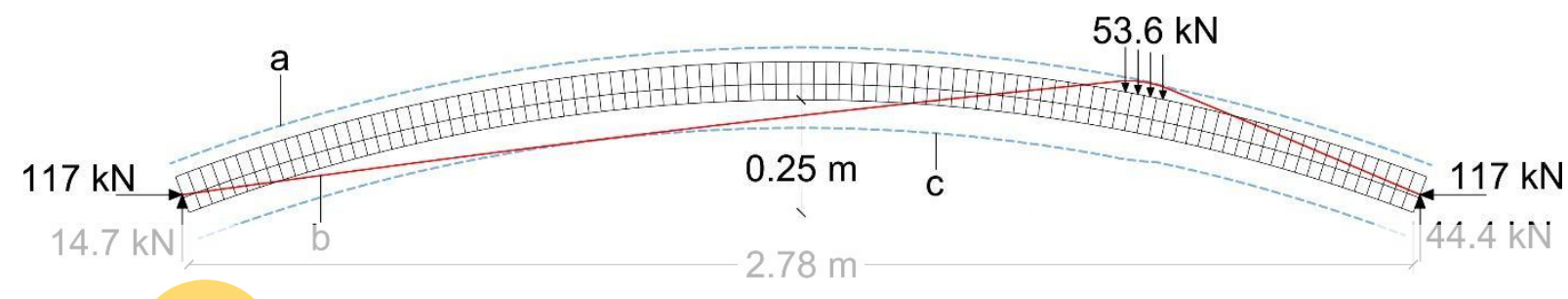

Figure 4: Application of the uniqueness theorem with ELARM to the tested vaults: a) upper virtual thickness, b) thrust line, and c) lower virtual thickness.

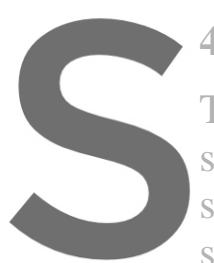

4 USING ELARM
The ELARM implementation, coded in Python, results in an
structural feedback [4]. As can be expected from any comput
speed, accuracy and the possibility to extend the analysis to

sizes or properties. The next subsections descitite

the design and structural analysis of reinforced masonry/concrete arches. As an example, a 14

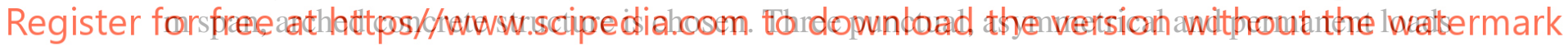
of $25 \mathrm{kN}$ are applied at 1/5,2/5 and 3/5 of the span. The vault is considered simply supported, i.e., each support consists of a contact surface, unable to take bending moments. The compressive strength of the concrete is taken as $40 \mathrm{~N} / \mathrm{mm}^{2}$ with a density of $2400 \mathrm{~kg} / \mathrm{m}^{3}$, and the steel's yield tensile strength for the reinforcement as $500 \mathrm{~N} / \mathrm{mm}^{2}$.

\subsection{Reinforcement optimisation}

A cross-section optimisation can be carried-out by adjusting the thickness of the structural layers and the amount and positions of the reinforcement, while accounting for different load combinations.

Among the many possibilities for the mentioned structure, Figure 5 and Figure 6 show the case of a $2.5 \mathrm{~m}$ rise, $1.0 \mathrm{~m}$ wide, $10 \mathrm{~cm}$ thick, parabolic arch with reinforcement placed at different levels of the cross-section. This could be the case of an already existing arch that needs reinforcement due to a new loading situation. The position of the reinforcement affects the virtual thickness and thus the possible positions of the thrust line, the final amount of reinforcement and the horizontal thrust. Reinforcement is placed at a distance of $25 \mathrm{~mm}$ from the extrados in the case of Figure 5 and at the same distance, but from the intrados, in Figure 6. 
Whereas in the case of Figure 5, an amount of reinforcement equivalent to a steel area of 700 $\mathrm{mm}^{2}$ was sufficient to obtain a solution, in the case of Figure 6, a steel area of $1000 \mathrm{~mm}^{2}$ is required. However, the option with less steel is, in this case, the one with a bigger horizontal thrust $(93 \mathrm{kN})$, due to a shallower thrust line solution (Figure 5).

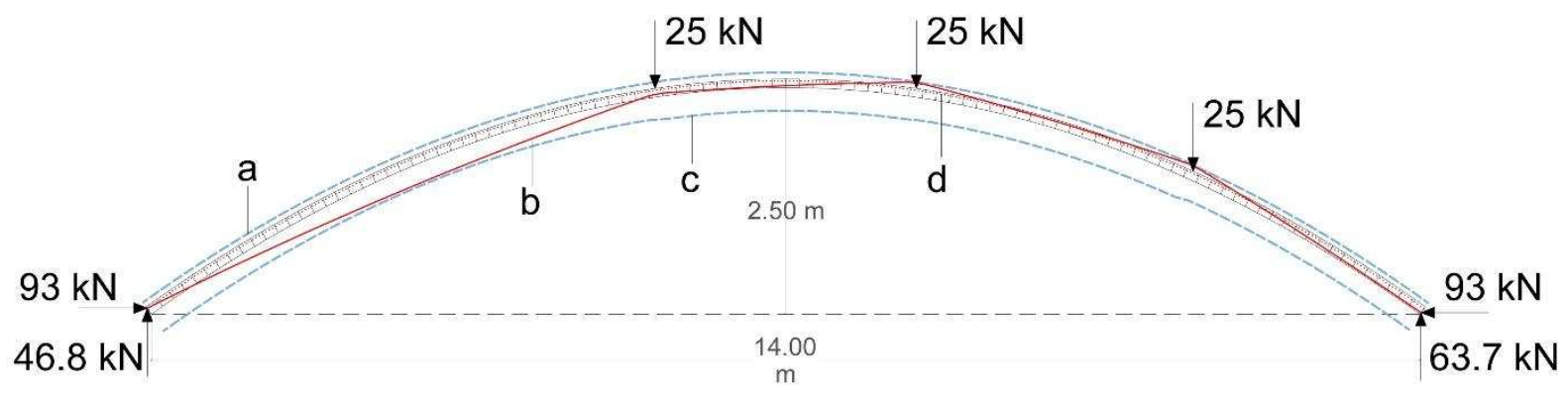

Figure 5: Structure with reinforcement at a distance of $25 \mathrm{~mm}$ from the extrados: a) upper virtual thickness, b) thrust line, c) lower virtual thickness, and d) reinforcement.
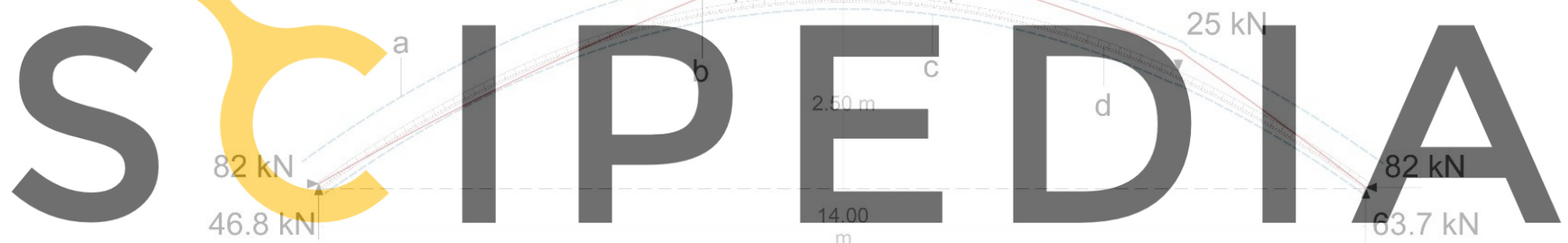

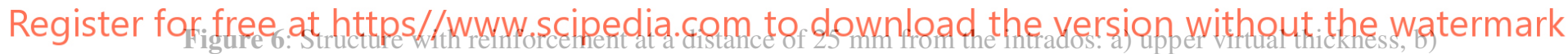
thrust line, c) lower virtual thickness, and d) reinforcement.

\subsection{Form-finding}

The use of the software Rhinoceros and the plug-in Grasshopper for the visualisation of graphical results and for the efficient introduction and modification of input parameters, allows for a fast and user-interactive form-finding process. The starting intrados of the analysed vault can be drawn as a curve in Rhinoceros, which can be easily modified through its control points. As the curve is being adjusted, calculations are computed and graphical updates are provided. The shape and parameters of the vault can be adapted and optimised according to the structural feedback received in near real-time. The presented tool allows the optimisation of the vault's shape regarding a defined loading condition, e.g. the permanent loads acting on the structure, by modifying the inputs that define the vault's geometry, and then adapting to the tool's structural feedback. A shape optimized for certain given loads would be one that includes within its virtual thickness boundaries, the thrust line supplied by ELARM with a minimum thickness 
and reinforcement. Therefore, instead of starting from an invariable, predefined shape and modifying thickness, material strength and/or reinforcement to increase the virtual boundaries and make the thrust line fit within, a form-finding process consists of modifying the geometrical inputs of the structure to make geometry and thrust line match as much as other design constraints would allow.

For the example of the previous section, maintaining the span and rise and taking into account the permanent and predominant loads, the resulting form-found shape is illustrated in Figure 7. Once a stable unreinforced masonry vault is found, the thickness of the masonry and the steel reinforcement position and amount can be updated considering other loading combinations, including further asymmetric live loads or if a higher safety factor is desired. Figure 8 shows an additional punctual load of $25 \mathrm{kN}$ at $4 / 5$ of the span. Keeping the thickness of $10 \mathrm{~cm}$ and adding reinforcement at a distance of $25 \mathrm{~mm}$ from the intrados, a steel area of 900 $\mathrm{mm}^{2}$ is required.

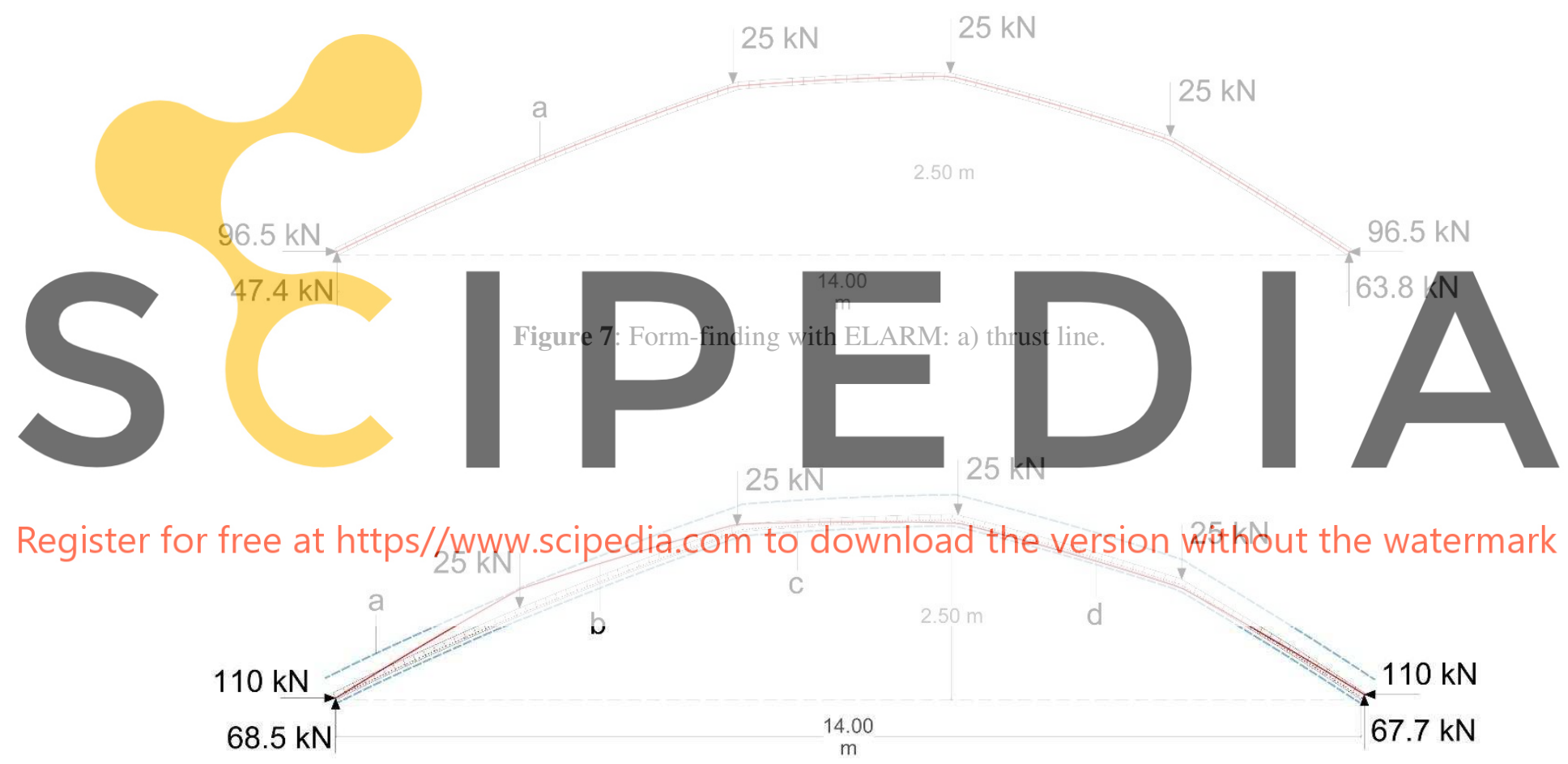

Figure 8: Form-finding with ELARM and an additional load: a) upper virtual thickness, b) thrust line, c) lower virtual thickness, and d) reinforcement.

\subsection{Beyond compression-only}

The addition of reinforcement to a masonry and/or concrete vault allows for the design of structures that are not restricted to being compression-only. Continuing with the example of the previous subsections, the proposal now is a structure made of three straight segments, being horizontal the middle one (Figure 9, Figure 10 and Figure 11). The advantages of this structure 
would be an easier and more economic construction thanks to the possibility to use straight formwork and the functionality of the horizontal surface. The thickness of the concrete structure is increased to $14 \mathrm{~cm}$ and reinforcement is placed at a central level of the cross-section.

Figure 9 illustrates the mentioned structure, simply supported and applying the three permanent, punctual loads. An amount of reinforcement equivalent to a steel area of $1400 \mathrm{~mm}^{2}$ is required to achieve stability. The same structure and conditions are repeated in Figure 10, except for the boundary conditions, which are now fixed supports, i.e., able to take bending moments. This new condition allows a higher range of possible thrust lines, as they must not end at the supports' contact surface, but can be at any point within the virtual thickness. In this case, reinforcement is decreased until $1100 \mathrm{~mm}^{2}$ (Figure 10). However, this amount of reinforcement would not be enough if an additional punctual load of $25 \mathrm{kN}$ at $4 / 5$ of the span would be included. Figure 11 shows this loading combination, for which a steel area of 1300 $\mathrm{mm}^{2}$ is required.

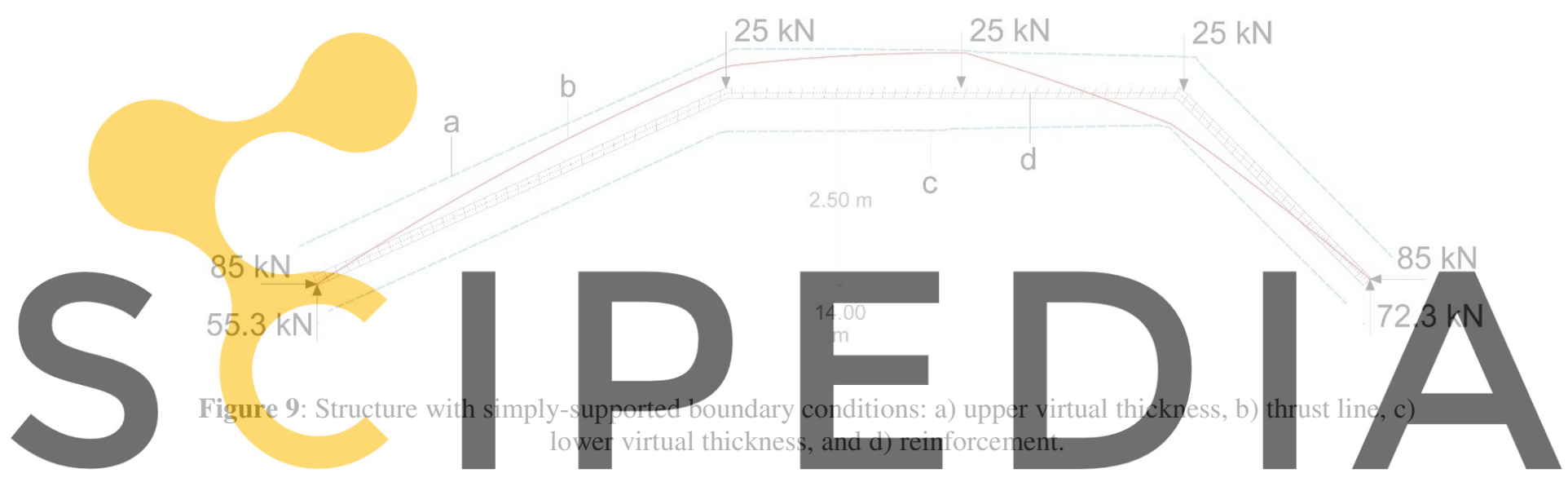

\section{Register for free at https//www.scipedia,com to download the version without the watermark}

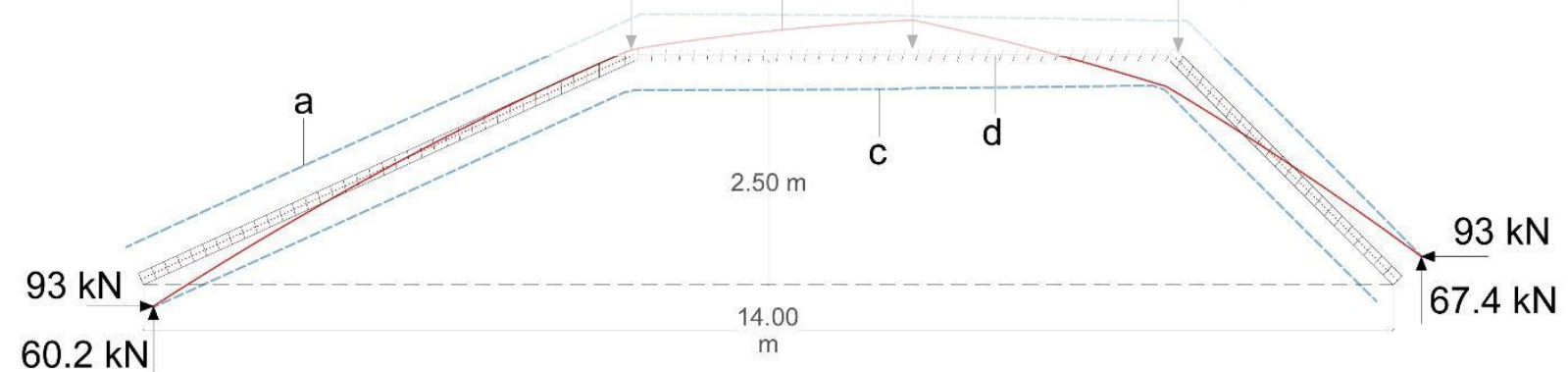

Figure 10: Structure with fixed supports: a) upper virtual thickness, b) thrust line, c) lower virtual thickness, and d) reinforcement. 


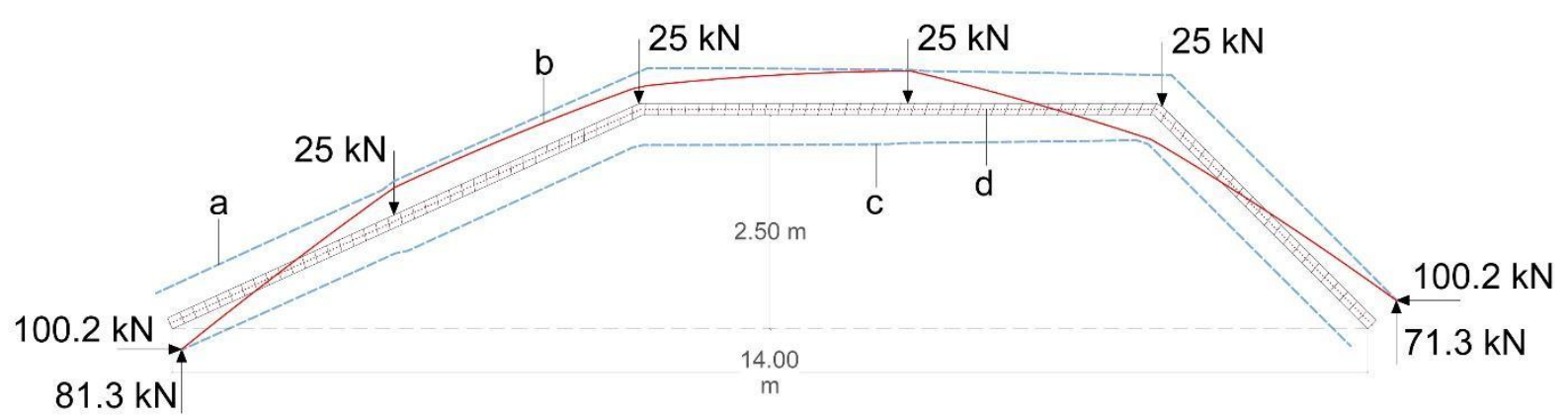

Figure 11: Structure with fixed supports and an additional load: a) upper virtual thickness, b) thrust line, c) lower virtual thickness, and d) reinforcement.

\section{CONCLUSIONS}

A method for the design and structural analysis of composite (masonry-concrete), arched structures has been presented. The method, called Extended Limit Analysis of Reinforced Masonry (ELARM), is based on traditional limit analysis, but extends it by considering the tensile capacity of the reinforcement and the compressive strength of the masonry and concrete. ELARM can also be applied to other structures with a sufficiently ductile response, such as

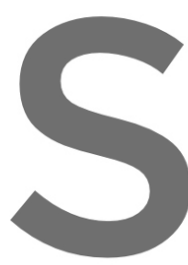

reinforced masonry of combining masonry a interactive and user-firie

The method and the research. The applicabiliting
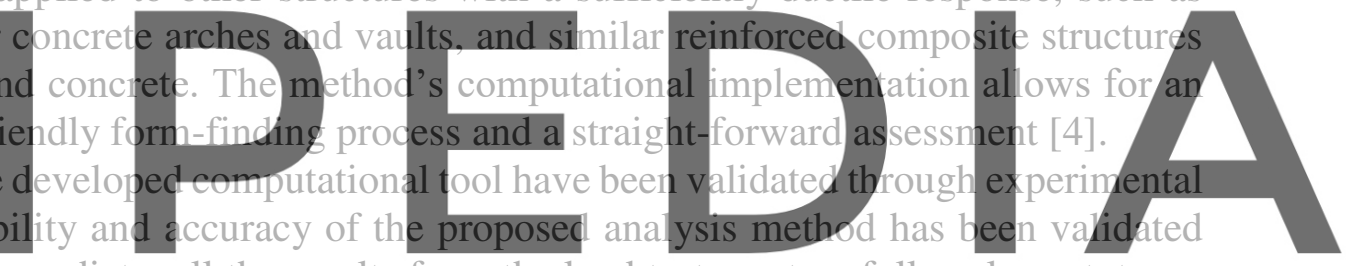

through its capacity to predict well the results from the load tests on two full-scale prototypes

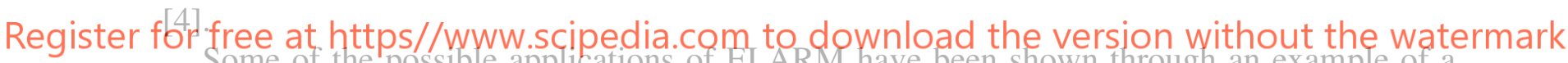
Some of the possible applications of ELARM have been shown through an example of a concrete structure with three punctual, permanent, asymmetrical loads. Different solutions have been discussed, including reinforcement optimisation, a form-found shape and a noncompression-only design. ELARM allows the exploration of a large range of possible solutions by modifying the thrust line, the position and amount of reinforcement, the shape of the structure and the load combinations with immediate, responsive, structurally informed feedback

Acknowledgements. This work was supported by the Swiss National Science Foundation (SNSF) [grant number P2EZP2_181591] and the Institute of Technology in Architecture (ITA) at the Swiss Federal Institute of Technology in Zurich (ETH Zurich). It was also sponsored by the construction company URCOTEX, from which Pep Brazo, Antonio Haro and Albert Martí are especially acknowledged. The construction of the prototypes was carried out together with Jordi Domènech, to whom the authors are very thankful.

Experimental support and facilities were kindly offered by the Laboratory for Technological Innovation in Structures and Materials (LITEM) at the Polytechnic University of Catalonia 
(UPC), from which Lluís Gil, Ernest Bernat, Christian Escrig and Luis Mercedes are especially acknowledged.

The presentation of this work at the 12th International Conference on Structural Analysis of Historical Constructions (SAHC 2020) was supported by the area of Architectural Structures within the Department of Architectural Technology at the Universitat Politècnica de Catalunya.

\section{REFERENCES}

[1] López López, D., Van Mele, T. and Block, P. Dieste, González Zuleta and Sánchez del Río: Three approaches to reinforced-brick shell structures. 10th International Conference on Structural Analysis of Historical Constructions (ed. Van Balen, K., \& Verstrynge, E.). London: Taylor \& Francis Group (2016).

[2] Meyer C, Sheer M. Do Concrete Shells Deserve Another Look? Concrete International, Oct. 2005: 43-50.

[3] Tang G. An Overview of Historical and Contemporary Concrete Shells, their Construction and Factors in their General Disappearance. International Journal of Space Structures 2015; 30(1).

[4] López López, D., Roca, P., Liew, A., Van Mele, T., \& Block, P. (2019b). Tile vaults as integrated formwork for reinforced concrete: Construction, experimental testing and a

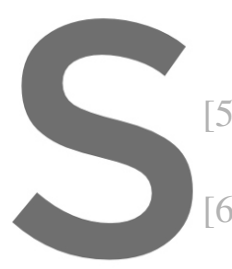
method for the desie $188,233-248$.

[5] López López D, Case Studies in Structural Engineering 2014 López López D, Construcción 2016; 68(544): e162, DOI:

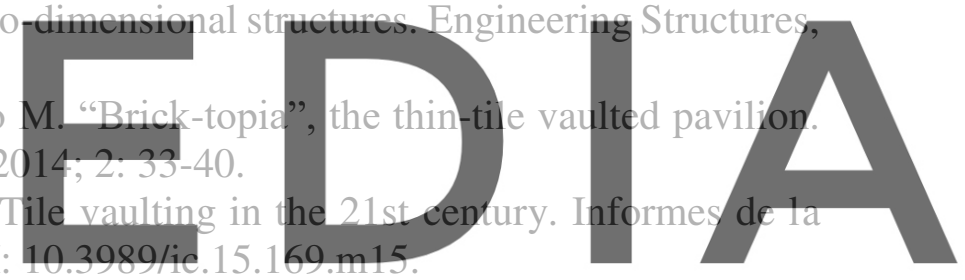

[7] López López, D., Van Mele, T., \& Block, P. (2019a). The combination of tile vaults with

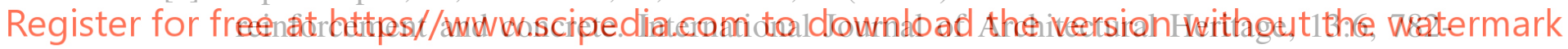
798. DOI: $10.1080 / 15583058.2018 .1476606$.

[8] Roca P, López-Almansa F, Miquel J, Hanganu A. Limit analysis of reinforced masonry vaults. Engineering Structures 2007; 29: 431-9.

[9] Heyman J. The stone skeleton. International Journal of Solids and Structures 1966; 2: 24979. 